\title{
WEAK FORMS OF SUPERCYCLITY AND A CLASS OF PARANORMAL OPERATORS
}

\author{
Sungeun Jung, InSOOK KIM AND EUngIL Ko
}

\begin{abstract}
In this paper, we give several properties of class $A$ operators, an interesting subclass of paranormal operators. In particular, we consider the operators $T \in \mathscr{L}(\mathscr{H})$ such that $T-\lambda$ is a class $A$ operator for every $\lambda \in \mathbb{C}$. We also provide some cases for class $A$ operators to have a nontrivial invariant subspace. Finally, we prove that there are no $N$-supercyclic class $A$ operators with trivial kernel for any positive integer $N$ and that weakly supercyclic class $A$ operators with trivial kernel must be normal.
\end{abstract}

Mathematics subject classification (2010): 47B20, 47A16.

Keywords and phrases: Class $A$ operator, invariant subspace, $N$-supercyclic, weakly supercyclic.

\section{REFERENCES}

[1] P. AienA, Fredholm and local spectral theory with applications to multipliers, Kluwer Academic Publishers, 2004.

[2] A. Aluthge And D. WANG, w-hyponormal operators, Int. Eq. Op. Th. 36 (2000), 1-10.

[3] T. ANDo, Operators with a norm condition, Acta Sci. Math. 33 (1972), 169-178.

[4] S. AnSARI, Hypercyclic and cyclic vectors, J. Func. Analysis 128 (1995), 374-383.

[5] C. Apostol, L. A. Fialkow, D. A. Herrero, and D. Voiculescu, Approximation of Hilbert space operators, Vol. II, Research Notes in Mathematics 102, Pitman, Boston, 1984.

[6] F. BAYART AND E. MATHERON, Hyponormal opertors, weighted shifts and weak forms of supercyclicity, Proc. Edinb. Math. Soc. 49 (2006), 1-15.

[7] P. S. BouRdon, Orbits of hyponormal operators, Mich. Math. J. 44 (1997), 345-353.

[8] M. Cho AND J. I. LeE, p-Hyponormality is not translation-invariant, Proc. Amer. Math. Soc. 131 (2003), 3109-3111.

[9] I. COLOJOARA AND C. FoIAs, Theory of generalized spectral operators, Gordon and Breach, New York, 1968.

[10] S. V. DJordjeVić And B. P. DugGal, Weyl's theorems and continuity of spectra in the class of p-hyponormal operators, Studia Math. 143(2000), 23-32.

[11] S. V. DJORDJEVIĆ AND D. S. DJORDJEVIĆ, Weyl's theorem: continuity of the spectrum and quasihyponormal operators, Acta Sci. Math. (Szeged) 64 (1998), 259-269.

[12] B. P. DugGal, Spectral continuity of $k$-th roots of hyponormal operators, Oper. Matrices 1(2007), 209-215.

[13] K. Dy Kema AND H. SChultz, Brown measure and iterates of the Aluthge transform for some operators arising from measurable actions, Trans. Amer. Math. Soc. 361 (2009), 6583-6593.

[14] N. S. Feldman, $N$-supercyclic operators, Studia Math. 151 (2002), 141-159.

[15] N. S. Feldman, V. G. Miller, And T. L. Miller, Hypercyclic and supercyclic cohyponormal operators, Acta Sci. Math. (Szeged) 68 (2002), 965-990.

[16] C. Foias And C. Pearcy, On hyperinvariant subspace problem, J. Funct. Anal. 219 (2005), 134142.

[17] T. FurUTA, Invitation to linear operators, Taylor and Francis, 2001.

[18] T. FurUtA, M. ITO, AND T. YAMAZAKI, A subclass of paranormal operators including class of log-hyponormal and several related classes, Scientiae Mathematicae, 1 (1998), 389-403. 
[19] D. A. HeRrero, Approximation of Hilbert space operators, Vol. 1, Second edition, Pitman Research Notes in Math. Series 224, 1989.

[20] M. ITO AND T. YAmAZAKI, Relations between two inequalities $\left(B^{\frac{r}{2}} A^{p} B^{\frac{r}{2}}\right)^{\frac{p}{p+r}} \geqslant B^{r}$ and $A^{p} \geqslant$ $\left(A^{\frac{p}{2}} B^{r} A^{\frac{p}{2}}\right)^{\frac{p}{p+r}}$ and their applications, Int. Eq. Op. Th. 44 (2002), 442-450.

[21] I. H. Jeon And B. P. Duggal, On operators with an absolute value conditions, J. Kor. Math. Soc. 41 (2004), 617-627.

[22] S. Jung, E. Ko, AND M. LeE, On class A operators, Studia Math. 198 (2010), 249-260.

[23] I. B. Jung, E. Ko, And C. Pearcy, Aluthge transforms of operators, Int. Eq. Op. Th. 37 (2000), $437-448$.

[24] R. LAnge And S. WAng, New approaches in spectral decomposition, Contemp. Math. 128, Amer. Math. Soc., 1992.

[25] K. B. Laursen And M. M. Neumann, Introduction to local spectral theory, London Math. Soc. Monograghs New Series. Claredon Press, Oxford, 2000.

[26] J. D. Newburgh, The variation of spectra, Duke Math. J. 8 (1951), 165-176.

[27] M. O. OTIENo, On quasi-similarity and w-hyponormal operators, Opuscula Math. 27(2007), 73-81.

[28] S. M. Patel, M. Chō, K. TAnahashi, And A. UChiyama, Putnam's inequality for class A operators and an operator transform by Chō and Yamazaki, Scientiae Mathematicae Japonicae 67 (2008), 393-402.

[29] A. PERIS, Multi-hypercyclic operators are hypercyclic, Math. Z. 236(2001), 779-786.

[30] H. Radjavi And P. Rosenthal, On roots of normal operators, J. Math. Anal. Appl. 34(1971), 653-664.

[31] H. Radjavi And P. Rosenthal, Invariant subspaces, Springer-Verlag, 1973.

[32] J. G. STAMPFLI, A local spectral theory for operators. V: spectral subspaces for hyponormal operators, Trans. Amer. Math. Soc. 217 (1976), 285-296.

[33] A. UchiYama, Berger-Shaw's theorem for p-hyponormal operators, Int. Eq. Op. Th. 33 (1999), $221-230$. 